\title{
The Demand for Non-Life Insurance: A Consumption-Oriented Model
}

\author{
by Antonio Falciglia*
}

\section{Introduction}

Most theoretical works dealing with the demand for non-life insurance are based on models in which the purchase of insurance is viewed as the exchange of a sum of money with certainty (the premium) for a sum of money with uncertainty (the compensation). The problem is solved by maximizing the expected utility of wealth, e.g. in Mossin [1968], Smith [1968], Borch [1977] and, for some aspects, also in Ehrlich-Becker [1972]. These approaches concentrate the analysis on individuals who are concerned with capital uncertainty only and rule out individuals who are concerned with income or near-future consumption uncertainty ${ }^{1}$.

In addition, in those papers, as well as in many others on the subject, the "delay mechanism" which is implicit in the service for coverage is not taken into account. This aspect of insurance is clearly expressed in Bohman [1979] and appears to be quite important. It implies that the demand for non-life insurance cannot be thought of as independent of the interest rate.

The purpose of this paper is to provide an alternative consumption-oriented model emphasizing the connection between the money market and the optimal insurance coverage. The model, described in section 2 , has been inspired by Stiglitz [1970]. It is based on the maximization of the expected utility of consumption in a two-periods framework. Insurance coverage and consumption expenditure are thus decided simultaneously.

* University of Venice. The author is grateful to prof. D. Salvatore of Fordham University in New York, prof. G. Palmerio of LUISS in Rome, prof. A. Montesano of University of Venice, Dr. G. Rich of Banque Nationale Suisse and to an anonymous referee for helpful comments. He alone is responsible for any remaining shortcomings.

${ }^{1}$ The distinction between individuals concerned with income uncertainty and those concerned with capital uncertainty has been drawn by J. Robinson [1952]. Stiglitz [1970] claims that the appropriate distinction is between those who are concerned with consumption in near future and those who are concerned with consumption in the more distant future. In any case, we cannot rule out the distinction in dealing with the demand for non-life insurance. See also Freimen-Gordon ([1968], pp. 94-109) for having underlined the importance of stating the consumer's objective when risk decisions are involved. 
In accordance with empirical observations, we consider in the model the insurer's optimal delay of payment and the price of consumer's time spent in order to get compensation payment after the realization of the risk. These elements will be represented by a function $\alpha$ (I) which increases the residual exposure, that is the loss suffered by the agent.

Section 3 deals with the determination of the optimum coverage level and investigates a special problem concerning full coverage contracts due to the existence of $\alpha$ (I). Finally, section 4 tries to investigate the relation between interest-rate changes and the demand for insurance.

\section{The model}

The model rests upon the following assumptions:

The economic agent has a two-periods consumption horizon and holds some initial (physical) assets yielding a return available for consumption in the second period. The entire wealth is used for consumption expenditures in the second period; there are no final assets.

First-period incomes are "outside-incomes" determined by the decisions of previous periods. Exposure to risk may reduce the value $\mathrm{H}$ of the initial wealth and the income stream deriving from it. The loss, denoted by $\mathrm{L}(0<\mathrm{L} \leqslant \mathrm{H})^{2}$, is a random variable with a known probability density function. Risks are insurable risks.

Second-period incomes derive from outside incomes, considered as given, and from "inside incomes". Inside incomes are formed by the assets value - $\mathrm{H}$ - at the beginning of period two plus the return - $\mathrm{y}-$ it has produced in period one. Both are dependent on residual exposure $\ell$ according to the hypothesis: $\psi(\ell)=\mathrm{H}(\ell)+\mathrm{y}(\ell), \psi^{\prime}<0$, $\psi "=0$ where $\ell$ will be defined later on.

L. Hence :

The insurance company pays a compensation for damages in proportion to the loss

(1) $\mathrm{H}^{\mathrm{a}}=\lambda \mathrm{H}$

(2) $I=\lambda L$

where $\mathrm{H}^{\mathrm{a}}$ is the insured value, $0 \leqslant \lambda \leqslant 1$, and $\mathrm{I}$ is the compensation paid by the insurer in case of losses. But the individual has to sustain some costs in getting compensation. These costs are specified by a function $\alpha$ (I). His net compensation will then be:

(3) $\mathrm{R}=\mathrm{I}-\alpha(\mathrm{I})$

${ }^{2}$ To simplify the analysis we have assumed $L>0$ and not $L \geqslant 0$. Such an assumption, as can be seen in Burger ([1967], p. 93) who employed it in a different context, is quite innocuous. 
and the residual exposure is defined as:

$$
\ell=(1-\lambda) L+\alpha(I)
$$

The function $\alpha$ (I) rests upon the existence of the insurer's optimal delay of payment and upon the price of the consumer's time in collecting informations about the claim and in ascertaining his right to the payment according to the policy conditions. It is an increasing function owing to the fact that the insurer will tend to delay the payment further as the compensation to be payed increases. The assumptions $1-\alpha,>0$ and $\alpha "<0$ seem also plausible and will be maintained throughout the paper.

The individual is assumed to behave consistently, to be risk-averse and to maximise an expected utility function, $U$, whose arguments are current and future consumption.

Under the above hypotheses the maximization problem is:

$$
\operatorname{Max} \Lambda=\mathrm{E}\left\{\mathrm{U}\left(\mathrm{c}_{0}, \mathrm{c}_{1}\right)\right\}
$$

subject to:

$$
c_{1}=\beta\left(w_{0}-c_{0}-\mu \lambda H\right)+w_{1}+\psi(\ell)
$$

where $\mu$ is the rate of premium, $\beta=1+\mathrm{r}(\mathrm{r}=$ rate of interest $), \mathrm{c}_{0}, \mathrm{c}_{1}$ are current and future consumption expenditures, $\mathrm{w}_{0}, \mathrm{w}_{1}$ are current and future outside incomes.

\section{The optimum level of coverage}

The problem specified by (5) and (6) is solved by applying standard differential calculus which allows us to write down the following first-order conditions for a maximum:

$$
\begin{aligned}
& \Lambda_{\mathrm{c}_{0}}=\mathrm{E}\left\{\mathrm{U}_{\mathrm{c}_{0}}-\beta \mathrm{U}_{\mathrm{c}_{1}}\right\}=0 \\
& \Lambda_{\lambda}=\mathrm{E}\left\{\left(-\beta \mu \mathrm{H}+\psi_{\lambda}\right) \mathrm{U}_{\mathrm{c}_{1}}\right\}=0 .
\end{aligned}
$$

At the points $c_{0}^{*}, \lambda^{*}$ determined by (7) and (8), we assume that the second order conditions for the existence of a maximum hold and that $\lambda^{*}$ is an interior solution.

The optimal level of coverage $\lambda^{*}$ can be suitably defined if we rearrange condition (8). Keeping in mind that there is no uncertainty on $\mathrm{r}$ and that

$$
\mathrm{E}\left\{\mathrm{U}_{\mathrm{c}_{1}} \cdot \psi_{\lambda}\right\}=\mathrm{E}\left\{\mathrm{U}_{\mathrm{c}_{1}}\right\} \cdot \mathrm{E}\left\{\psi_{\lambda}\right\}+\operatorname{cov}\left\{\mathrm{U}_{\mathrm{c}_{1}}, \psi_{\lambda}\right\},
$$

we can rewrite equation (8) as :

(8) $\frac{\mathrm{E}\left\{\psi_{\lambda}\right\}}{\mu \mathrm{H}}=\beta-\frac{1}{\mu \mathrm{H}} \cdot \frac{\operatorname{cov}\left\{\mathrm{U}_{\mathrm{c}_{1}}, \psi_{\lambda}\right\}}{\mathrm{E}\left\{\mathrm{U}_{\mathrm{c}_{1}}\right\}}$. 
Equation (8') states that, at the equilibrium $\lambda^{*}$, the expected marginal return from insurance equals the money rate of interest minus a component representing the influence of risk on the individual's preferences. Thus, the rate of interest is one of the elements determining optimal coverage. Therefore, pure risk management cannot be considered as independent of financial management. A connection has been established between the non-life insurance market and the monetary market. This relation will be analyzed further in section 4.

We must now focus on the sign of $\operatorname{cov}\left\{\mathrm{U}_{\mathrm{c}_{1}}, \psi_{\lambda}\right\}$. Since $\mathrm{E}\left\{\psi_{\lambda}\right\}$ represents the expected marginal benefit from insurance and $\mu \mathrm{H}$ is the premium when $\lambda=1$ (marginal premium), we have in practice $\mathrm{E}\left\{\psi_{\lambda}\right\}<\mu \mathrm{H}$. Thus, in order to get the solution for (8'), we expect the sign of $\operatorname{cov}\left\{U_{c_{1}}, \psi_{\lambda}\right\}$ to be positive. To prove that this is the case, we observe that

$$
\operatorname{cov}\left\{\mathrm{U}_{\mathrm{c}_{1}}, \psi_{\lambda}\right\} \lessgtr 0 \text { if and only if } \psi_{\lambda \mathrm{L}} \lessgtr 0^{3}
$$

provided $\psi_{\mathrm{L}}=\psi^{\prime}(\ell)\left[1-\lambda\left(1-\alpha^{\prime}\right)\right]<0$.

Since $\psi_{\lambda L}=\psi^{\prime}(\ell)\left(\alpha^{\prime}-1+\lambda L \alpha^{\prime \prime}\right)>0, \operatorname{cov}\left\{U_{c_{1}}, \psi_{\lambda}\right\}>0$.

Conditions $\psi_{\mathrm{L}}<0, \psi_{\lambda}>0, \psi_{\lambda \lambda}=\psi^{\prime} \alpha^{\prime \prime} \mathrm{L}>0, \psi_{\lambda \mathrm{L}}>0$ and the corresponding $\operatorname{cov}\left\{\mathrm{U}_{\mathrm{c}_{1}}, \psi_{\lambda}\right\}>0$ are related to the decrease in variance of second-period income $\left(\sigma_{\psi}^{2}\right)$ as the level of coverage, $\lambda$, increases. This reflects the fundamental property of insurance i.e., a tool for achieving stability.

It is worth to note that condition (8') does not rule out the possibility of full coverage contracts $\left(\lambda^{*}=1\right)$. In fact, assuming $\psi[\ell(\lambda, L)]=-(1-\lambda) L-\alpha(I),\left(8^{\prime}\right)$ can be rewritten as:

$$
\mathrm{E}\left\{\frac{\mathrm{L}\left(1-\alpha^{\prime}\right)_{\lambda=1}}{\mu \mathrm{H}}\right\}=\beta-\frac{\left\{\mathrm{U}_{\mathrm{C}_{1}}, \mathrm{~L}\left(1-\alpha^{\prime}\right)_{\lambda=1}\right\}}{\mu \mathrm{HE}\left\{\mathrm{U}_{\mathrm{c}_{1}}\right\}}
$$

which can be verified if, as is the case, $L-\alpha \lambda=1>0^{4}$. Such a result can easily be explained if we recall that, because of the function $\alpha(I)$, variability in the consumption stream can never be eliminated completely; $\alpha(1)$ modifies the entire structure of the risk implicit in the insurance contract and may therefore increase optimal coverage despite the reduction it produces in the total benefit from insurance.

${ }^{3}$ The proof is simple. First we note that $\psi \lambda=\psi^{\prime}(\ell)$. [ $\left.\left(\alpha^{\prime}(\mathrm{I})-1\right) \mathrm{L}\right]>0, \mathrm{U}_{\mathrm{c}_{1} \mathrm{c}_{1}}<0$ and that between $\psi$ and $\mathrm{U}_{\mathrm{c}_{1}}$ a functional link exists through the utility function and the budget constraint. Since $\psi$ decreases as $\mathrm{L}$ increases, $\mathrm{U}_{\mathrm{c}_{1}}$ is an increasing function of $\mathrm{L}$. Thus the sign of $\operatorname{cov}\left\{\mathrm{U}_{\mathrm{e}_{1}}, \psi_{\lambda}\right\}$ depends upon the variation of $\psi_{\lambda}$ as $\mathrm{L}$ varies into $0<\mathrm{L} \leqslant \mathrm{H}$, that is upon the sign of $\psi_{\lambda_{L}}$. Since $\psi \lambda_{L}>0, U_{c_{1}}$ and $\psi_{\lambda}$ have positive correlation. Hence, cov $\left\{U_{c_{1}}, \psi_{\lambda}\right\}>0$. 


\section{4. "Comparative Statics" analysis}

In this section the conventional comparative statics analysis will be carried out. In particular we examine the effects upon $\lambda^{*}$ of variations in:

a) the present and future outside incomes $\mathrm{w}_{0}$ and $\mathrm{w}_{1}$;

b) the rate of premium $\mu$;

c) the rate of interest $r$.

We assume in the following discussion, as in Levhary-Weiss [1974], that the utility function is separable so that present and future consumption are independent goods, i.e., $\mathrm{U}\left(\mathrm{c}_{0}, \mathrm{c}_{1}\right)=\mathrm{U}_{0}\left(\mathrm{c}_{0}\right)+\mathrm{U}_{1}\left(\mathrm{c}_{1}\right) ; \mathrm{U}_{0}^{\prime}\left(\mathrm{c}_{0}\right)$ and $\mathrm{U}_{1}^{\prime}\left(\mathrm{c}_{1}\right)>0 ; \mathrm{U}_{0}{ }_{0}\left(\mathrm{c}_{0}\right)$ and $\mathrm{U}_{1}^{\prime \prime}\left(\mathrm{c}_{1}\right)<0$.

By differentiating first order conditions $(7)$ and $(8)$ with respect to $\mathrm{z}_{\mathrm{i}}(\mathrm{i}=1,2,3,4)$ where $z_{i}$ denotes respectively parameters $w_{0}, w_{1}, \mu, \beta$ - we get the linear system:

(10)

$$
\left\{\begin{array}{cc}
\Lambda_{\mathrm{c}_{0} c_{0}} & \Lambda_{\mathrm{c}_{0} \lambda} \\
\Lambda_{\lambda \mathrm{c}_{0}} & \Lambda_{\lambda \lambda}
\end{array}\right\} \cdot\left\{\begin{array}{l}
\frac{\delta \mathrm{c}_{0}}{\delta \mathrm{z}_{\mathrm{i}}} \\
\frac{\delta \lambda}{\delta \mathrm{z}_{\mathrm{i}}}
\end{array}\right\}=-\left\{\begin{array}{c}
\Lambda_{\mathrm{c}_{0} \mathrm{z}_{\mathrm{i}}} \\
\Lambda_{\lambda \mathrm{z}_{\mathrm{i}}}
\end{array}\right\}
$$

Solving for $\frac{\delta \lambda}{\delta z_{i}}$, we obtain:

$$
\mathrm{D} \frac{\delta \lambda}{\delta \mathrm{z}_{\mathrm{i}}}=-\Lambda_{\mathrm{c}_{0} \mathrm{c}_{0}} \Lambda_{\lambda \mathrm{z}_{\mathrm{i}}}+\Lambda_{\lambda \mathrm{c}_{0}} \Lambda_{\mathrm{c}_{0} \mathrm{z}_{\mathrm{i}}}
$$

where $\mathrm{D}=\Lambda_{\mathrm{c}_{0} \mathrm{c}_{0}} \cdot \Lambda_{\lambda \lambda}-\Lambda_{\lambda \mathrm{c}_{0}}^{2}>0 ; \Lambda_{\mathrm{c}_{0} \mathrm{c}_{0}}=\mathrm{U}_{0}^{\prime \prime}\left(\mathrm{c}_{0}\right)+\beta^{2} \mathrm{E}\left\{\mathrm{U}_{1}^{\prime \prime}\left(\mathrm{c}_{1}\right)\right\}<0$ and $\Lambda_{\lambda c_{0}} \equiv \Lambda_{c_{0} \lambda}=-\beta E\left\{U_{1}^{\prime \prime}\left(c_{1}\right)\left[\psi \lambda\left(\lambda^{*}, L\right)-\beta \mu H\right]\right\}$.

The solution for each specified parameter is obtained by specifying the corresponding $\Lambda_{\lambda z_{\mathrm{i}}}, \Lambda_{\mathrm{c}_{0} \mathrm{z}_{\mathrm{i}}}$.

In particular, with respect to $\mathrm{w}_{0}$ and $\mathrm{w}_{1}$ the solutions are:

$$
\mathrm{D} \frac{\delta \lambda^{*}}{\delta \mathrm{z}_{1}}=\Lambda_{\lambda \mathrm{c}_{0}} \cdot \mathrm{U}_{0}^{\prime \prime}\left(\mathrm{c}_{0}\right)
$$

${ }^{4} \mathrm{~L}\left(1-\alpha^{\prime}\right) \lambda=1$ denotes the partial derivative of $\psi(\ell)$ for $\lambda=1$ and is defined only in the lefthand side. Furthermore, in this case $\psi \lambda_{\mathrm{L}}=1-\alpha^{\prime}-\alpha^{\prime \prime} \cdot \lambda_{\mathrm{L}}>0$ for $\lambda=1$. 


$$
\mathrm{D} \frac{\delta \lambda^{*}}{\delta \mathrm{z}_{2}}=\frac{1}{\beta} \Lambda \lambda \mathrm{c}_{0} \cdot \mathrm{U}_{0}^{\prime \prime}\left(\mathrm{c}_{0}\right)
$$

So that $\mathrm{D} \frac{\delta \lambda^{*}}{\delta \mathrm{z}_{\mathrm{i}}} \lessgtr 0(\mathrm{i}=1,2)$ if $\Lambda \lambda \mathrm{c}_{0} \gtrless 0$. It can be shown that at the optimum $\Lambda_{\lambda c_{0}} \gtrless 0$ if and only if $R_{A}^{\prime}\left(c_{1}\right) \lessgtr 0^{5}$ where $R_{A}\left(c_{1}\right)=-\frac{U_{1}^{\prime \prime}\left(c_{1}\right)}{U_{1}^{\prime}\left(c_{1}\right)}$ is the absolute risk aversion and $R_{A}^{\prime}\left(c_{1}\right) \lessgtr 0$ denotes respectively decreasing, constant and increasing absolute risk aversion. These results show the great difficulty of characterising, on a theoretical base only, the response to the variation of outside incomes of the aggregate (market) demand for non-life insurance.

The effect upon $\lambda^{*}$ due to variations in $\mu$ (the slope of the individual's demand for non-life insurance) is expressed by the following equation:

$$
\mathrm{D} \frac{\delta \lambda^{*}}{\delta \mathrm{z}_{3}}=\beta \mathrm{H} \Lambda_{\mathrm{c}_{0} \mathrm{c}_{0}} \cdot \mathrm{E}\left\{\mathrm{U}_{1}^{\prime}\left(\mathrm{c}_{1}\right)\right\}-\lambda^{*} \mathrm{HD} \frac{\delta \lambda^{*}}{\delta \mathrm{z}_{1}}
$$

If the hypothesis of increasing absolute risk aversion is accepted $\left(\mathrm{R}_{\mathrm{A}}^{\prime}\left(\mathrm{c}_{1}\right)>0\right),(14)$ states that the demand for non-life insurance is a decreasing function of the unit premium $\mu$. As in standard consumption theory, the variation in premium produces two effects: a "substitution effect" $\left(\beta \Lambda_{\mathrm{c}_{0} c_{0}} \cdot \mathrm{E}\left\{\mathrm{U}_{1}^{\prime}\left(\mathrm{c}_{1}\right)\right\}\right)$ which is negative and an "income effect" which in this case is positive. Hence, under the above hypothesis, insurance cannot be an inferior good. The same is true if there is constant absolute risk aversion $\left(R_{A}^{\prime}\left(c_{1}\right)=0\right)$. In this case the income-effect is zero. However the sign of $\mathrm{D} \frac{\delta \lambda^{*}}{\delta \mu}$ is ambiguous and nothing can be said about the slope of the individual's demand in the case of decreasing absolute risk aversion $\left(\mathrm{R}_{\mathrm{A}}^{\prime}\left(\mathrm{c}_{1}\right)<0\right)$.

The variation of optimal coverage due to an increase of the interest rate is shown by equation (15):

$$
\mathrm{D} \frac{\delta \lambda^{*}}{\delta \mathrm{z}_{4}}=\mathrm{E}\left\{\mathrm{U}_{1}^{\prime}\left(\mathrm{c}_{1}\right)\right\}\left[\mu \mathrm{HU} \mathrm{U}_{0}^{\prime \prime}\left(\mathrm{c}_{0}\right)+\beta \mathrm{E}\left\{\mathrm{U}_{1}^{\prime \prime}\left(\mathrm{c}_{1}\right) \psi_{\lambda}\right\}\right]+\mathrm{D} \frac{\mathrm{S}^{*}}{\beta} \frac{\delta \lambda^{*}}{\delta \mathrm{z}_{1}}
$$

$$
\text { where } \mathrm{S}^{*}=\mathrm{w}_{0}-\mathrm{c}_{0}^{*}-\lambda * \mu \mathrm{H}
$$

\footnotetext{
${ }^{5}$ To prove this, let us begin with rewriting $\Lambda_{\lambda_{c_{0}}}$ as in the following: $\Lambda_{\lambda_{c_{0}}}=\beta E\left\{R_{A}\left(c_{1}\right) \cdot\right.$ $\left.U_{1}^{\prime}\left(c_{1}\right)\left[\psi_{\lambda}\left(\lambda^{*}, L\right)-\beta \mu H\right]\right\}=\beta E\left\{R_{A}\left(c_{1}\right)\right\} \cdot E\left\{U_{1}^{\prime}\left(c_{1}\right)\left[\psi_{\lambda}\left(\lambda^{*}, L\right)-\beta \mu H\right]\right\}+\beta \operatorname{cov}\left\{R_{A}\left(c_{1}\right)\right.$, $\left.\mathrm{U}_{1}^{\prime}\left(\mathrm{c}_{1}\right)\left[\psi_{\lambda}\left(\lambda^{*}, \mathrm{~L}\right)-\beta \mu \mathrm{H}\right]\right\}$. But, from the first order condition (8), the first term is zero; thus the sign of $\Lambda_{\lambda_{c_{0}}}$ is the sign of the covariance in the second term. Since: a) $\psi_{\lambda L}>0$, b) $U_{1}^{\prime}\left(c_{1}\right)<0$, c) $\psi_{\mathrm{L}}<0, \mathrm{U}_{1}^{\prime}\left(\mathrm{c}_{1}\right)$ and $\left[\psi_{\lambda}\left(\lambda^{*}, \mathrm{~L}\right)-\beta \mu \mathrm{H}\right]$ are monotonically increasing functions of $\mathrm{L}$. Hence,
} 
As one could expect, the total effect upon $\lambda^{*}$ due to variations of $\beta$ is the sum of two partial effects, (substitution and income effects) the first of which is always negative. As can be seen, the income effect, $\frac{S^{*}}{\beta} \cdot \mathrm{D} \frac{\delta \lambda^{*}}{\delta \mathrm{z}_{\mathrm{i}}}$ does not depend only upon the hypothesis of decreasing, constant or increasing absolute risk aversion $\left(R^{\prime}\left(c_{1}\right) \lessgtr 0\right)$ but also upon the sign of $S^{*}$, i.e. if at the optimum position, the agent is a net saver $\left(S^{*}>0\right)$ a zero saver $\left(S^{*}=0\right)$ or a net borrower $\left(S^{*}<0\right)$ in the first period.

If $\mathrm{R}_{\mathrm{A}}^{\prime}\left(\mathrm{c}_{1}\right)=0$ (constant absolute risk aversion) whatever the sign of $\mathrm{S}^{*}$, we have a zero income effect; therefore $\mathrm{D} \frac{\delta \lambda^{*}}{\delta \mathrm{z}_{4}}<0$, i.e. an increase in $\beta$ reduces the demand for non-life insurance. The same is true if $S^{*}=0$, whatever the sign of $R_{A}^{\prime}\left(c_{1}\right)$.

Four other cases may occur:<smiles>[R14][Ca][Se][Se]O</smiles>

$\mathrm{R}_{\mathrm{A}}^{\prime}\left(\mathrm{c}_{1}\right)>0<\begin{aligned} & \mathrm{S}^{*}>0 \\ & \mathrm{~S}^{*}<0\end{aligned}$ a)

b)

c)

d)

Under hypotheses a) and d) $\mathrm{D} \frac{\delta \lambda^{*}}{\delta \mathrm{z}_{4}}<0$ because the substitution and income effects have the same negative sign. Under hypotheses b) and c) $\mathrm{D} \frac{\delta \lambda^{*}}{\delta \mathrm{z}_{4}}$ has an ambiguous sign and nothing can be said as far as the reaction of demand is concerned. In conclusion, when changes in monetary policies and/or liquidity preference cause an interest rate variation in money markets, the demand response to these variations are unambiguously determined for these individuals who alternatively: 1) have a constant absolute risk aversion, 2) have a zero net saving in the first period, 3) have a decreasing absolute risk aversion and are net savers in period one, 4) have an increasing absolute risk aversion and are net

\section{Continued}

their product increases monotonically as $\mathrm{L}$ increases. Keeping in mind that $c_{1}$ is a monotonically decreasing function of $L$, we get that $R_{A}\left(c_{1}\right)$ increases monotonically, decreases monotonically or is constant if and only if $R_{A}^{\prime}\left(c_{1}\right) \lessgtr 0$, that is if there is decreasing, constant or increasing absolute risk aversion. As a result, $\operatorname{cov}\left\{R_{A}\left(c_{1}\right), U_{1}^{\prime}\left(c_{1}\right)\left[\psi_{\lambda}\left(\lambda^{*}, L\right)-\beta \mu H\right]\right\} \gtreqless 0$ if and only if $R_{A}^{\prime}\left(c_{1}\right) \lessgtr 0$. The above results are morc general and, because of condition $\psi_{\mathrm{L}}<0$, are different from that of LevhariWeiss [1974]. 
borrowers in period one. In the remaining two cases the reaction of individual demand is ambiguous. Owing to this "ambiguity" at the individual's level, we cannot rule out $a$ priori that the aggregate (market) demand for non-life insurance reacts positively to the increases of the rate of interest and viceversa. Some recent studies (Headen-Lee [1974]) have empirically investigated such relations in the life insurance sector and tend to show that the ambiguity may disappear as a result of statistical tests.

\section{Concluding remarks}

Our purpose has been to formulate a consumption oriented model of the demand for non-life insurance in order to take into account the behaviour of individuals who are concerned with income or near-future consumption uncertainty. The model, different from similar models concerned with capital uncertainty, emphasizes also the role of the interest rate in determining the demand for non-life insurance. This role, as we pointed out, derives from the delay mechanism implicit in insurance coverage. However, the analysis carried out in determining the relation between non-life insurance demand and the interest rate, has been unconclusive. Only if we accept the hypothesis of decreasing absolute risk aversion, the relation is negative and increases of interest rate discourage the demand for non-life insurance, provided the agent is a net saver.

The model allows the investigation of the effect of outside income increases upon the demand. Quite surprisingly we have found that insurance coverage is an inferior good if decreasing absolute risk aversion prevails. Owing to that, in this case, the demand slope is ambiguous. Only if the quite unfavorable hypothesis of increasing absolute risk aversion is accepted we can graph a downward-sloping insurance demand curve.

It is also worth to note the role of function $\alpha(\mathrm{I})$. We think that this function plays an important role in determining the demand for insurance. Although we know very little about $\alpha(\mathrm{I})$, the hypothesized structure seems to be rather plausible. Because of this function and in this special case, full insurance coverage cannot be ruled out.

Even if it has not been done in the present paper, the model can easily take into account, the effects of uncertainty in the interest rate, of imperfect capital market, and of a progressive income tax ${ }^{6}$.

\footnotetext{
${ }^{6}$ These exercises have been carried out in a similar model by Levhary-Weiss [1974] as far as interest rate uncertainty and capital market imperfection are concerned, and by Falciglia [1978] as far as progressive income tax is concerned.
} 


\section{REFERENCES}

BOHMAN, H. [1979]: "A mathematical model of insurance business and how it may be used", The Geneva Papers on Risk and Insurance, 11 (January 1979), 34-39.

BORCH, K. [1977]: "Introduction" to: The Geneva Papers on Risk and Insurance, 5 (February 1977), 3-8.

BURGER, E. [1967]: Introduzione alla Teoria dei Giochi, Franco Angeli, Milan.

EHRLICH, I. and G.S. BECKER [1972]: "Market insurance, self-insurance and self-protection", Journal of Political Economy, 80 (July-August 1972), 623-648.

FALCIGLIA, A. [1978]: "Strutture del mercato del lavoro e l'effetto rischio dei differenziali intersettoriali sulla domanda di istruzione", Rivista Internazionale di Scienze Sociali, 27-54.

FREIMEN, M. and M.J. GORDON [1968]: "Investment Behavior with utility a concave function of wealth", in K. Borch and J. Mossin (Eds.) Risk and Uncertainty, New York, 94-109.

HEADEN, R.S. and J.F. LEE [1974]: "Life insurance demand and household portfolio behavior", Journal of Risk and Insurance, 41 (December 1974), 220-234.

LEVHARY, D. and Y. WEISS [1974]: "The effect of risk on the investment in human capital", American Economic Review, 64 (December 1974), 951-963.

MOSSIN, J. [1968]: “Aspects of rational insurance purchasing”, Journal of Political Economy, 76 (July-August 1968), 553-568.

ROBINSON, J. [1952]: The Rate of Interest, Mac Millan, London.

SMITH, V.L. [1968]: “Optimal insurance coverage”, Journal of Political Economy, 76 (JanuaryFebruary 1968), 68-77.

STIGLITZ, J. [1970]: "A consumption-oriented theory of the demand for financial assets and the term structure of interest rate", Review of Economic Studies, 37 (July 1970), 321-351. 